\title{
ALOX12 gene polymorphisms and serum selenium status in elderly osteoporotic patients
}

\author{
Atiyeh Al-e-Ahmad ${ }^{1,2, A-D, F}$, Hadi Parsian ${ }^{3, A-F}$, Mojtaba Fathi ${ }^{2, A-F}$, Soghrat Faghihzadeh ${ }^{4, A, C, E, F}$, \\ Seyed Reza Hosseini ${ }^{5, A, B, F}$, Haji Ghorban Nooreddini, ${ }^{6, A, B, F}$, Abbas Mosapour ${ }^{7, B, F}$ \\ ${ }^{1}$ Mobility Impairment Research Center, Health Research Institute, Babol University of Medical Sciences, Iran \\ ${ }^{2}$ Department of Biochemistry and Nutrition, Faculty of Medicine, Zanjan University of Medical Sciences, Iran \\ ${ }^{3}$ Cellular and Molecular Biology Research Center, Health Research Institute, Babol University of Medical Sciences, Iran \\ ${ }^{4}$ Department of Biostatistics and Epidemiology, Faculty of Medicine, Zanjan University of Medical Sciences, Iran \\ ${ }^{5}$ Social Determinants of Health Research Center, Health Research Institute, Babol University of Medical Sciences, Iran \\ ${ }^{6}$ Department of Internal Medicine, Ayatollah Rouhani Hospital, Babol University of Medical Sciences, Iran \\ ${ }^{7}$ Department of Biochemistry, School of Medicine, Babol University of Medical Sciences, Iran \\ A - research concept and design; $\mathrm{B}$ - collection and/or assembly of data; C - data analysis and interpretation; \\ $D$ - writing the article; $E$ - critical revision of the article; $F$ - final approval of the article
}

Address for correspondence

Hadi Parsian

E-mail: hadiparsian@yahoo.com

Funding sources

This work was financially supported in a large part by research grant No. A-12-802-3 from the Department of Biochemistry and Nutrition, Zanjan University of Medical Sciences, Iran.

Conflict of interest

None declared

\section{Acknowledgements}

We would like to thank Babol University of Medical Sciences, Iran, for their professional assistance and consultation. We are greatly indebted to the families who participated in this study, without whom this work would not have been possible.

Received on 0ctober 15, 2016 Reviewed on January 24, 2017 Accepted on July 5, 2017

\begin{abstract}
Background. Osteoporosis is a systemic bone disease which leads to a reduction in bone mass. Many studies have shown that up to $80 \%$ of bone mineral density (BMD) variations are attributed to genetic factors. Arachidonate 12-lipoxygenase enzyme, encoded by the ALOX12 gene, produces lipid peroxides as reactive oxygen species (ROS), leading to oxidative stress and the development of osteoporosis. Selenium (Se) is incorporated into selenoproteins, which may reduce the risk of osteoporosis.
\end{abstract}

Objectives. We aimed to investigate the association of 2 ALOX12 single nucleotide polymorphisms (SNPS) and serum Se level with lumbar spine and femoral neck BMD among elderly individuals living in Amirkola, Iran.

Material and methods. The study consisted of 180 individuals aged $\geq 60$ years $(90$ healthy and 90 osteoporotic patients). We examined the effect of 2 ALOX12 SNPs (rs2292350 and rs9897850), using the polymerase chain reaction - restriction fragment length polymorphism (PCR-RFLP) on both BMD regions measured by dual energy $X$-ray absorptiometry (DXA). Serum Se level was measured using an atomic absorption spectrophotometer PGG990 AAS (PG Instruments Ltd., Lutterworth, USA).

Results. The rs2292350 SNP showed a significant association with femoral neck BMD ( $p=0.04$ ). Moreover, in terms of serum Se level, a significant difference was found between the patient group (57.58 $\pm 25.54 \mu \mathrm{g} / \mathrm{L})$ and the control group $(81.09 \pm 25.58 \mu \mathrm{g} / \mathrm{L})(\mathrm{p}<0.001)$. In addition, individuals with higher serum Se levels also had higher BMD of the lumbar spine $\left(r^{2}=0.392 ; p<0.001\right)$ and the femoral neck $\left(r^{2}=0.478 ; p<0.001\right)$.

Conclusions. The results suggested that genetic variation in ALOX12 might influence BMD variations in our recruited participants. As for the patients with lower serum Se levels, it was observed that serum Se deficiency was accompanied by some ALOX12 variation, contributing to the development of osteoporosis.

Key words: osteoporosis, single nucleotide polymorphism, bone mineral density, ALOX12, selenium

DOI

10.17219/acem/75689

Copyright

Copyright by Author(s)

This is an article distributed under the terms of the Creative Commons Attribution Non-Commercial License (http://creativecommons.org/licenses/by-nc-nd/4.0/) 


\section{Introduction}

Osteoporosis is a systemic bone disease mostly occurring in elderly individuals. In this disease, disturbance in bone remodeling (bone resorption and formation) leads to a bone mass reduction, bone fragility, and eventually, to fracture. Osteoporotic fracture may cause disability, decreased quality of life, and ultimately, mortality - it affects all aspects of the patient's life. ${ }^{1}$ It has been estimated that over 200 million people suffer from osteoporosis worldwide. ${ }^{2}$ There have also been studies reporting the rate of this disease in a local region; for example, in 2009, an Iranian multi-center study indicated that $70 \%$ of women and $50 \%$ of men aged $\geq 50$ years suffered from osteoporosis or osteopenia. ${ }^{3}$

Peak bone mineral density (BMD) as a major determinant of bone strength achieved in early adulthood plays an important role in the prediction of osteoporotic fracture in later life. ${ }^{1}$ In addition to many confirmed factors, such as race, sex, age, nutrition, hormonal status, menopausal state, smoking, alcohol intake, and physical activity, there are many studies that support the remarkable influence of genetic factors on bone strength. Studies show that up to $80 \%$ of BMD variation is attributable to genetic factors. ${ }^{4-7}$

A link between hip, spine and wrist BMD and the arachidonate 12-lipoxygenase ( $A L O X 12)$ gene has been reported, and some researchers have suggested that $A L O X 12$ is a susceptible gene for BMD variation. ALOX12 belongs to the arachidonate lipoxygenase enzyme super-family, which catalyzes the insertion of molecular oxygen into polyunsaturated fatty acids, such as arachidonic acid..$^{8,9}$

The product of $A L O X 12$ activity, i.e., 12-hydroperoxyeicosatetraenoic acid (12-HPETE), serves as an endogenous ligand for the peroxisome proliferator-activated receptors (PPARs), which inhibit osteoblastogenesis and increase adipogenesis from a common progenitor - the mesenchymal stem cells (MSCs) of bone marrow. ${ }^{10-12}$ Therefore, $A L O X 12$ activation could result in the upregulation of the pathway of PPARs, subsequently decreasing osteoblastogenesis and BMD. ${ }^{13,14}$ Accordingly, several single nucleotide polymorphisms (SNPs) in ALOX12 have been suggested as being associated with BMD variations in humans, but the results are controversial., ${ }^{1,4,5,7,15}$

Selenium (Se) is an essential trace element that incorporates into selenoproteins as selenocysteine - the $21^{\text {st }}$ amino acid. Various members of the glutathione peroxidase (GPx) family (including phospholipid hydroperoxide glutathione peroxidase - PHGPx) are well-known selenoproteins with antioxidant capacity that play an important role in the scavenging of lipid peroxide products. ${ }^{16,17}$ Therefore, 12-HPETE serves as a reactive oxygen species (ROS), quickly converting to 12-hydroxyeicosatetraenoic acid (12-HETE) by peroxidase 2,4 . Therefore, a decrease of Se can interfere with the turnover of lipid peroxidation, resulting in ROS accumulation that leads to cellular and extracellular damage in bone turnover, such as inhibition of osteoblastic differentiation, which is a major contributor to the development of osteoporosis. ${ }^{18,19}$
Although there is no clear mechanism indicating a relationship between the Se status and osteoporosis development, reports show that antioxidant supplementation reduces the risk of osteoporosis via an improvement in antioxidant capacity. ${ }^{16,18,20,21}$ Furthermore, Se intake would reduce the risk of osteoporotic hip fracture in a population-based casecontrol study and Se deficiency also resulted in a reduction in femur and tibia BMD in rats. Therefore, Se deficiency can be considered a putative risk factor of osteoporosis. ${ }^{22,23}$

To the best of our knowledge, there have been no reports on the status of $A L O X 12$ polymorphisms and Se in osteoporotic individuals in our area. Therefore, we aimed to investigate the association of 2 ALOX12 polymorphisms (rs2292350 and rs9897850) and serum Se with lumbar spine and femoral neck BMD in this population.

\section{Material and methods}

\section{Participants}

From among 1,616 elderly participants in the Amirkola Health and Aging Project (AHAP), we randomly selected 90 out of 558 osteoporotic individuals ( 45 males and $45 \mathrm{fe}$ males) as the study group and 90 out of 326 age- and gender-matched individuals (45 males and 45 females) as control subjects. ${ }^{24}$ The remaining participants had osteopenia. Informed consent was obtained from each participant and the study was approved by the Zanjan University of Medical Sciences (Iran) Ethics Committee. The osteoporosis status was determined by BMD measurement. All selected participants were $\geq 60$ years old and they had never taken any medication related to BMD or bone turnover, or Se supplementary drugs, and they were all non-smokers. None of the participants had renal or metabolic bone disease.

\section{Bone mineral density measurement}

Bone mineral density $\left[\mathrm{g} / \mathrm{cm}^{2}\right]$ of the lumbar spine (L1L4) and proximal femur were measured by a dual energy X-ray absorptiometry (DXA) densitometer, using a Lexxos densitometer (DMS, Montpellier, France). According to the World Health Organization (WHO) criteria, the participants were categorized into 2 separate groups, osteoporotic and normal. Subjects with a BMD of 2.5 standard deviations (SD) or below the average value for young healthy adults (i.e., a T-score of $<-2.5 \mathrm{SD}$ ) were considered osteoporotic patients, and subjects with a T-score of $>-1.0 \mathrm{SD}$ were considered normal subjects. ${ }^{25}$

\section{Serum selenium measurement}

Serum Se levels were measured by an atomic absorption spectrophotometer PG990 AAS (PG Instruments Ltd., Lutterworth, USA) equipped with a graphite furnace. Each serum sample was first diluted with deionized water (1:1); then, $10 \mu \mathrm{L}$ of each diluted sample was injected into the graphite 
furnace. The working standard solution was prepared from stock standards of Se, according to Standard Reference Material (SRM) from National Institutes of Standards and Technology (NIST); $1000 \mathrm{mg} / \mathrm{L}$ for AAS (selenium dioxide in nitric acid $0.5 \mathrm{~mol} / \mathrm{L}$ (Merch KGaA, Darmstadt, Germany)). The operating parameters for measuring serum Se levels were set as recommended by the manufacturer (wavelength: $196 \mathrm{~nm}$; bandwidth: $0.4 \mathrm{~nm}$; and lamp current: $5 \mathrm{~mA}$ ).

\section{Genotyping}

\section{Polymorphism selection}

Using extensive literature searches, among all known polymorphisms of $A L O X 12,2$ SNPs (rs9897850 and rs2292350) were selected on the basis of other researchers' findings. ${ }^{1,4,5,7}$ Both SNPs were listed in the National Center for Biotechnology Information (NCBI) SNP database and happened to be very common (minor allele frequencies $>0.35$ ).

\section{Polymerase chain reaction}

Genomic DNA was extracted from whole blood using a QIAamp DNA Blood Mini Kit (QIAGEN Korea Ltd., Seoul, Korea) and stored at $-20^{\circ} \mathrm{C}$. The polymerase chain reaction (PCR) was performed using 2 pairs of forward and reverse primers (CinnaGen, Tehran, Iran) as follows: forward - 5'AGTGTTCTCATCTATGTTCGC3', reverse - 5'CCCAGACTAGCCCAAACC3' for rs9897850 targeting the promoter region, and forward -5'AGTAGGTGTAGGTGTATAGGTGAC3', reverse - 5'TGTGGTTAGCCGTATTCC3' for rs2292350 targeting the intron 2 region of the $A L O X 12$ gene.

The PCR was carried out using a PCR Master Mix 2X (CinnaGen) according to the manufacturer's protocol, adjusted to a total reaction mixture of $25 \mu \mathrm{L}$, containing $50 \mathrm{ng}$ of total DNA template. Amplification was performed using a DNA thermal cycler (Analytik Jena AG, Jena, Germany) for 35 cycles $\left(93^{\circ} \mathrm{C}, 60 \mathrm{~s} ; 57^{\circ} \mathrm{C}, 60 \mathrm{~s} ; 72^{\circ} \mathrm{C}, 60 \mathrm{~s}\right)$ with an initial heating at $95^{\circ} \mathrm{C}$ for $5 \mathrm{~min}$ and a final extension for $5 \mathrm{~min}$ at $72^{\circ} \mathrm{C}$. The PCR products were analyzed by $1 \%$ agarose gel electrophoresis and visualized with a gel documentation and analysis system (Gel Doc ${ }^{\mathrm{TM}}$ EZ System; Bio-Rad Laboratories, Hercules, USA) after staining by DNA safe stain
(CinnaGen). The PCR product size was 215 bp for rs 9897850 and $300 \mathrm{bp}$ for rs2292350.

\section{Restriction Fragment Length Polymorphism (RFLP)}

Each PCR product in a dose of $10 \mu \mathrm{L}$ was digested using $5 \mathrm{U}$ of HinfI (BIORON GmbH, Ludwigshafen, Germany) and PscI (PciI) (Thermo Scientific, Waltham, USA) restriction enzyme per $20 \mu \mathrm{L}$ of reaction mixture at $37^{\circ} \mathrm{C}$ for $3 \mathrm{~h}$. The digestion products were analyzed by $1.5 \%$ agarose gel electrophoresis after staining by DNA safe stain, and were then visualized using UVdoc.

\section{Statistical analysis}

Statistical analysis was performed using SPSS 16.0 (SPSS Inc., Chicago, USA). The genotype frequencies of both SNPs were estimated by allele counting for all participants, and the Hardy-Weinberg equilibrium (HWE) was assessed using the $X^{2}$ test. $^{26}$ The linkage disequilibrium (LD) and haplotyping were analyzed using CubeX online software (www.oege.org/software/cubex) (Gaunt et al.; licensee BioMed Central Ltd., London, UK). ${ }^{27}$ Values of $\mathrm{p} \leq 0.05$ were considered statistically significant.

Differences in the frequency of genotypes between the osteoporotic patients and the gender-matched normal controls were tested using $X^{2}$ tests. The correlation of the genotypes and lumbar spine or femoral neck BMD adjusted for age and gender was analyzed using a one-way analysis of variance (ANOVA) followed by Tukey's test.

In the next step, differences in serum Se level between the patients and the controls were tested using an independent sample t-test. In addition, the correlation between Se level and lumbar spine or femoral neck BMD was evaluated using Pearson's bivariate correlation.

\section{Results}

\section{Clinical characteristics}

A total of 90 individuals with osteoporosis ( 45 males and 45 females) were recruited as the study group and 90 aged-

Table 1. The general characteristics of participants

\begin{tabular}{|c|c|c|c|c|c|c|}
\hline Participants & \multicolumn{3}{|c|}{ Normal controls } & \multicolumn{3}{|c|}{ Osteoporotic patients } \\
\hline Gender & male & female & total & male & female & total \\
\hline Number of patients & 45 & 45 & 90 & 45 & 45 & 90 \\
\hline Age [years] & $68.11 \pm 6.36^{\#}$ & $64.93 \pm 4.69$ & $66.52 \pm 5.78$ & $69.73 \pm 6.83^{\#}$ & $66.04 \pm 4.88$ & $67.89 \pm 6.19$ \\
\hline Height $[\mathrm{cm}]$ & $164.93 \pm 5.30^{*}$ & $154.04 \pm 5.82^{*}$ & $159.49 \pm 7.78^{*}$ & $158.52 \pm 7.08$ & $150.41 \pm 6.07$ & $154.47 \pm 7.72$ \\
\hline Weight [kg] & $77.58 \pm 10.88^{*}$ & $76.30 \pm 9.89^{*}$ & $76.94 \pm 10.36^{*}$ & $58.41 \pm 10.58$ & $63.56 \pm 11.84$ & $60.98 \pm 11.46$ \\
\hline BMI $\left[\mathrm{kg} / \mathrm{m}^{2}\right]$ & $28.50 \pm 3.62^{*}$ & $32.18 \pm 3.96^{*}$ & $30.34 \pm 4.20^{*}$ & $23.20 \pm 3.71$ & $28.02 \pm 4.60$ & $25.61 \pm 4.81$ \\
\hline Lumbar spine BMD $\left[\mathrm{g} / \mathrm{cm}^{2}\right]$ & $1.12 \pm 0.12^{\# *}$ & $1.04 \pm 0.09^{*}$ & $1.08 \pm 0.11^{*}$ & $0.70 \pm 0.13$ & $0.67 \pm 0.12$ & $0.69 \pm 0.12$ \\
\hline Femoral neck BMD $\left[\mathrm{g} / \mathrm{cm}^{2}\right]$ & $1.05 \pm 0.11^{\# *}$ & $0.98 \pm 0.07^{*}$ & $1.02 \pm 0.10^{*}$ & $0.69 \pm 0.11$ & $0.73 \pm 0.12$ & $0.71 \pm 0.12$ \\
\hline Serum Se $[\mu \mathrm{g} / \mathrm{L}]$ & $87.15 \pm 26.08^{\# *}$ & $73.68 \pm 23.19^{*}$ & $81.09 \pm 25.58^{*}$ & $62.14 \pm 28.66^{\#}$ & $54.91 \pm 23.55$ & $57.58 \pm 25.54$ \\
\hline
\end{tabular}

Data is presented as mean \pm standard deviation (SD); BMI - body mass index; BMD - bone mineral density; ${ }^{*}$ statistical significance between normal controls and osteoporotic patients; ${ }^{*}$ statistical significance between males and females of each group. 
-matched normal participants (45 males and 45 females) were selected to be the control group. Table 1 represents the demographic and morphometric characteristics and the BMD values of all participants.

\section{Allelic frequencies and haplotype structure}

Two SNPs (rs9897850 and rs2292350) in the ALOX12 gene were genotyped using the polymerase chain reaction - restriction fragment length polymorphism (PCRRFLP). Neither SNP was found to be in HWE due to high $\mathrm{p}$-values of the $\chi^{2}$ test. The genotype characteristics of the participants are outlined in Table 2. The 2 SNPs analyzed in $A L O X 12$ - rs9897850 and rs2292350 - are located in the promoter region and in the intron 2 region of chromosome 17p13, respectively. The LD was calculated for the $A L O X 12$ gene polymorphisms (rs9897850 and rs2292350) for the whole population $\left(D^{\prime}=0.305 ; r^{2}=0.0628\right)$. There was no significant correlation between any of the 4 possible haplotypes and the risk of disease.

\section{Association between single nucleotide polymorphisms and bone mineral density variations}

The effect of each SNP genotype on the lumbar spine and femoral neck BMD parameters was examined using ANOVA. For rs9897850, there was no significant difference in either lumbar spine or femoral neck BMD, but a marginal trend was observed involving rs2292350.

The rs2292350 SNP showed the most significant association for femoral neck BMD ( $\mathrm{p}=0.04$ ), as individuals homozygous for the $G$ allele at rs2292350 had $0.17 \pm 0.7 \mathrm{~g} / \mathrm{cm}^{2}$ higher mean femoral neck BMD than those homozygous for the A allele ( $\mathrm{p}=0.037)$ (Table 3$)$.

\section{Serum selenium concentration}

A significant difference was found between the osteoporotic patients $(57.58 \pm 25.54 \mu \mathrm{g} / \mathrm{L})$ and the controls $(81.09 \pm 25.58 \mu \mathrm{g} / \mathrm{L})$ in terms of serum Se levels $(\mathrm{p}<0.001)$. However, the mean Se concentration in male subjects happened to be significantly higher compared to females ( $p=0.002$ ). Individuals with higher Se levels also had higher BMD of the lumbar spine $\left(\mathrm{r}^{2}=0.392 ; \mathrm{p}<0.001\right)$ and the femoral neck $\left(\mathrm{r}^{2}=0.478 ; \mathrm{p}<0.001\right)$, but no association was found for genotype frequency of either SNP.

\section{Discussion}

Previous studies have shown a linkage between hip, spine and wrist BMD and the $17 \mathrm{p} 13$ chromosomal region where the $A L O X 12$ gene has been mapped to. ${ }^{8,9} 12$-hydroperoxyeicosatetraenoic acid, i.e., the product of $A L O X 12$ activity, serves as an endogenous ligand for PPARs, which inhibits osteoblastogenesis. ${ }^{11,12}$ Therefore, ALOX12 has been considered a candidate gene for the development of osteoporosis and several SNPs in the human ALOX12 gene have been suggested as being associated with BMD in humans. ${ }^{1,4,5,7,15}$

In the present study, 2 polymorphisms (rs9897850 and rs2292350) of $A L O X 12$ were investigated for a probable association with BMD in the elderly population of Amirkola, Iran. None of the mentioned polymorphisms were found to be in HWE. Deviations from HWE may have happened as a result of a new mutation, inbreeding, selective mating, or a genotyping error. ${ }^{28,29}$

The rs2292350 polymorphism was significantly associated with reduced femoral neck BMD in both genders.

Table 2. The genotype properties of ALOX12 gene SNPS

\begin{tabular}{|c|c|c|c|c|c|}
\hline Variable & $\begin{array}{l}\text { Common } \mathrm{Hz} \\
\mathrm{n}(\% \text { within } \\
\text { the group) }\end{array}$ & $\begin{array}{c}\text { Het } \\
\mathrm{n} \text { (\% within } \\
\text { the group) }\end{array}$ & $\begin{array}{l}\text { Rare } \mathrm{Hz} \\
\mathrm{n} \text { (\% within } \\
\text { the group) }\end{array}$ & $\begin{array}{l}\text { Overall } p \text {-value } \\
\text { for } x^{2} \text { test }\end{array}$ & $\begin{array}{c}\text { OR } \\
\text { rare } \mathrm{Hz} \text { vs common } \mathrm{Hz}(\mathrm{Cl}) \text {, } \\
\text { p-value }\end{array}$ \\
\hline rs9897850 & $\mathrm{C} / \mathrm{C}$ & $\mathrm{C} / \mathrm{T}$ & $\mathrm{T} / \mathrm{T}$ & \multirow{3}{*}{0.784} & \multirow{3}{*}{$\begin{array}{c}0.85 \\
(0.33-2.15) \\
0.728\end{array}$} \\
\hline normal controls & $24(26.7)$ & $50(55.6)$ & $16(17.8)$ & & \\
\hline osteoporotic patients & $23(25.6)$ & $54(60)$ & $13(14.4)$ & & \\
\hline rs2292350 & $\mathrm{G} / \mathrm{G}$ & G/A & $\mathrm{A} / \mathrm{A}$ & \multirow{3}{*}{0.054} & \multirow{3}{*}{$\begin{array}{c}9.15 \\
(1.06-79.11) \\
0.044\end{array}$} \\
\hline normal controls & $34(37.8)$ & $55(61.1)$ & $1(1.1)$ & & \\
\hline osteoporotic patients & $26(28.9)$ & $57(63.3)$ & $7(7.8)$ & & \\
\hline
\end{tabular}

SNPS - single nucleotide polymorphisms; Hz - homozygote; Het - heterozygote; $\mathrm{N}$ - number of patients; OR - odds ratio; Cl - confidence interval.

Table 3. The association of ALOX12 genotypes with BMD

\begin{tabular}{|c|c|c|c|c|c|c|c|c|}
\hline \multirow{3}{*}{$\begin{array}{c}\text { BMD } \\
{\left[\mathrm{g} / \mathrm{cm}^{2}\right]}\end{array}$} & \multicolumn{8}{|c|}{ Genotype } \\
\hline & \multicolumn{4}{|c|}{ rs9897850 } & \multicolumn{4}{|c|}{ rs2292350 } \\
\hline & $\mathrm{CC}$ & CT & TT & $\mathrm{p}$-value & GG & $\mathrm{GA}$ & $\mathrm{AA}$ & $p$-value \\
\hline Lumbar spine & $0.88 \pm 0.23$ & $0.88 \pm 0.23$ & $0.91 \pm 0.23$ & 0.84 & $0.90 \pm 0.23$ & $0.88 \pm 0.23$ & $0.74 \pm 0.18$ & 0.19 \\
\hline Femoral neck & $0.87 \pm 0.19$ & $0.85 \pm 0.18$ & $0.9 \pm 0.22$ & 0.44 & $0.90 \pm 0.18$ & $0.86 \pm 0.19$ & $0.72 \pm 0.13$ & 0.04 \\
\hline
\end{tabular}

Data is presented as mean \pm standard deviation (SD); BMD - bone mineral density. 
Our results showed that individuals homozygous for the A allele of this polymorphism had the lowest BMD values.

Similarly to our findings, it was found by Mullin et al. that rs2292350 was significantly associated with spine and various hip BMD parameters in postmenopausal women; however, they report that homozygotes for the A allele of rs2292350 had significantly higher spine BMD compared with the heterozygous group, as opposed to our results. ${ }^{7}$

Harsløf et al. reported that heterozygous individuals for both polymorphisms (rs9897850 and rs2292350) had lower lumbar spine BMD and an increased risk of vertebral fractures compared with homozygous individuals for either allele. ${ }^{4}$ In addition, Xiao reported the rs2292350 polymorphism to be significantly associated with BMD in the lumbar spine, the femoral neck and the total hip in Chinese families. ${ }^{5}$

In another study, Ichikawa et al. investigated the relationship between 12 SNPs in ALOX12 and BMD variations in the hip and the spine in a healthy American population. They observed that up to $3 \%$ of the spine BMD variation in men and $0.8 \%$ of that in women is due to genetic variations in $A L O X 12$. Both rs9897850 and rs2292350 were associated with lumbar spine BMD in both genders, but the most significant association was found with rs 9897850 in men. ${ }^{1}$

Neither SNP in our study was in a haplotype block due to a weak LD with each other. Therefore, we did not observe any association of the abovementioned SNPs with lumbar spine or femoral neck BMD in the haplotype analysis, but Ichikawa et al. reported that a common haplotype containing both rs 9897850 and rs2292350 was associated with high lumbar spine BMD in women and low lumbar spine BMD in men. ${ }^{1}$

The inhibition of osteoblastic differentiation of bone MSCs due to oxidative stress is a major contributor to the development of osteoporosis. ${ }^{19,30-33}$ Basu et al. found that the levels of 8-iso-PGF2a (a major F2-isoprostane) as a biomarker of oxidative stress negatively correlated with BMD. They concluded that an increase in oxidative stress was related to a reduction in BMD values. ${ }^{34}$

Experimental evidence suggests that Se might decrease the risk of osteoporosis via incorporating into selenoproteins, such as GPx, and can act as an antioxidant against oxidative damage. ${ }^{23,35}$ Chen et al. in their study on human epidermoid carcinoma cells observed that GPx and PHGPx activity decreased with a lowering of the glutathione (GSH) content. ${ }^{36}$ In another study, this team observed that an overexpression of the Se-dependent PHGPx enzyme could reduce $A L O X 12$ activity, and in this manner it was possible to decrease the risk of developing osteoporosis. ${ }^{37,38}$ Besides, Liu et al. showed that selenite $\left(\mathrm{Na}_{2} \mathrm{SeO}_{3}\right)$, as a selenium supplement, could increase the activity and gene expression of GPx. This Se supplementation is able to reverse the reduced antioxidant capacity and GSH, in addition to its ability to suppress the ROS production in $\mathrm{H}_{2} \mathrm{O}_{2}$-treated MSCs. ${ }^{18}$
Odabasi et al. measured the Se concentration in plasma and red blood cells in postmenopausal women with osteoporosis in comparison with BMI-matched healthy postmenopausal women. They did not observe any significant difference between the 2 groups. ${ }^{39}$ In another study, Arikan et al. investigated serum Se levels in postmenopausal women with osteoporosis or osteopenia and healthy controls, and did not find any correlation between Se and lumbar spine BMD. ${ }^{40}$ In contrast, in this study we observed higher serum Se levels in the controls than in the osteoporotic patients ( $\mathrm{p}<0.001$ ), and individuals that had higher Se levels had higher BMD in the femoral neck and the lumbar spine.

\section{Conclusions}

The effect of 2 SNPs in ALOX12 on the BMD of both the lumbar spine and the femoral neck was investigated in the present study. Our findings suggest the significance of ALOX12 in both BMD variations and in the development of osteoporosis. In addition, the antioxidant effect of PHGPX, which is due to Se as an essential trace element acting as a cofactor, may be able to reduce $A L O X 12$ activity. The results of this study can open the door to a better understanding of the mechanism of Se action in osteoporosis. Surely, further investigation into this area would be needed in order to improve our knowledge of osteoporosis development.

\section{References}

1. Ichikawa $\mathrm{S}$, Koller $\mathrm{DL}$, Johnson $\mathrm{ML}$, et al. Human $A L O X 12$, but not ALOX15, is associated with BMD in white men and women. $J$ Bone Miner Res. 2006;21:556-564.

2. Cooper C, Campion G, Melton III LJ. Hip fractures in the elderly: A worldwide projection. Osteoporos Int. 1992;2:285-289.

3. Rahnavard Z, Zolfaghari M, Hossein-Nezad A, Vahid Dastgerdi M. The incidence of osteoporotic Hip fracture: Iranian Multicenter Osteoporosis Study (IMOS). Res J Biol Sci. 2009;4:171-173.

4. Harsløf T, Husted LB, Nyegaard M, et al. Polymorphisms in the ALOX12 gene and osteoporosis. Osteoporos Int. 2011;22:2249-2259.

5. Xiao WJ, Ke YH, He JW, et al. Polymorphisms in the human ALOX12 and $A L O X 15$ genes are associated with peak bone mineral density in Chinese nuclear families. Osteoporos Int. 2012;23:1889-1897.

6. Brown LB, Streeten EA, Shapiro JR, et al. Genetic and environmental influences on bone mineral density in pre-and post-menopausal women. Osteoporos Int. 2005;16:1849-1856.

7. Mullin B, Spector T, Curtis C, et al. Polymorphisms in ALOX12, but not ALOX15, are significantly associated with BMD in postmenopausal women. Calcif Tissue Int. 2007;81:10-17.

8. Devoto M, Shimoya K, Caminis J, et al. First-stage autosomal genome screen in extended pedigrees suggests genes predisposing to low bone mineral density on chromosomes 1p, $2 p$ and $4 q$. Eur J Hum Genet. 1998;6:151-157.

9. Deng HW, Xu FH, Huang QY, et al. A whole-genome linkage scan suggests several genomic regions potentially containing quantitative trait loci for osteoporosis. J Clin Endocrinol Metab. 2002;87:5151-5159.

10. Gimble JM, Zvonic S, Floyd ZE, Kassem M, Nuttall ME. Playing with bone and fat. J Cell Biochem. 2006;98:251-266.

11. Lecka-Czernik B, Moerman EJ, Grant DF, Lehmann JM, Manolagas SC, Jilka RL. Divergent effects of selective peroxisome proliferator-activated receptor- $\gamma 2$ ligands on adipocyte versus osteoblast differentiation. Endocrinology. 2002;143:2376-2384.

12. Khan $E, A b u$-Amer Y. Activation of peroxisome proliferator-activated receptor- $\gamma$ inhibits differentiation of preosteoblasts. J Lab Clin Med. 2003;142:29-34. 
13. Akune T, Ohba $S$, Kamekura $S$, et al. PPAR- $\gamma$ insufficiency enhances osteogenesis through osteoblast formation from bone marrow progenitors. J Clin Invest. 2004;113:846.

14. Kawaguchi $H$, Akune $T$, Yamaguchi $M$, et al. Distinct effects of PPAR- $\gamma$ insufficiency on bone marrow cells, osteoblasts, and osteoclastic cells. J Bone Miner Metab. 2005;23:275-279.

15. Xiong DH, Shen $\mathrm{H}$, Zhao LJ, et al. Robust and comprehensive analysis of 20 osteoporosis candidate genes by very high-density singlenucleotide polymorphism screen among 405 white nuclear families identified significant association and gene-gene interaction. JBone Miner Res. 2006;21:1678-1695.

16. Ebert R, Jakob F. Selenium deficiency as a putative risk factor for osteoporosis. Int Congr Ser. 2007;1297:158-164.

17. Müller C, Wingler K, Brigelius-Flohe R. 3'UTRs of glutathione peroxidases differentially affect selenium-dependent mRNA stability and selenocysteine incorporation efficiency. Biol Chem. 2003;384:11-18.

18. Liu H, Bian W, Liu S, Huang K. Selenium protects bone marrow stromal cells against hydrogen peroxide-induced inhibition of osteoblastic differentiation by suppressing oxidative stress and ERK signaling pathway. Biol Trace Elem Res. 2012;150:441-450.

19. Manolagas SC. From estrogen-centric to aging and oxidative stress: A revised perspective of the pathogenesis of osteoporosis. Endocr Rev. 2010;31:266-300.

20. Mackinnon E, Rao A, Josse R, Rao L. Supplementation with the antioxidant lycopene significantly decreases oxidative stress parameters and the bone resorption marker N-telopeptide of type I collagen in postmenopausal women. Osteoporos Int. 2011;22:1091-1101.

21. Ruiz-Ramos M, Vargas LA, Van der Goes TF, Cervantes-Sandoval A, Mendoza-Nunez V. Supplementation of ascorbic acid and alpha-tocopherol is useful to preventing bone loss linked to oxidative stress in elderly. J Nutr. 2010;14:467-472.

22. Zhang J, Munger RG, West NA, Cutler DR, Wengreen HJ, Corcoran CD. Antioxidant intake and risk of osteoporotic hip fracture in Utah: An effect modified by smoking status. Am JEpidemiol. 2006;163:9-17.

23. Moreno-Reyes R, Egrise D, Neve J, Pasteels JL, Schoutens A. Selenium deficiency-induced growth retardation is associated with an impaired bone metabolism and osteopenia. J Bone Miner Res. 2001;16:1556-1563.

24. Hosseini SR, Cumming RG, Kheirkhah F, et al. Cohort profile: The Amirkola Health and Ageing Project (AHAP). Int J Epidemiol. 2014;43:1393-1400.

25. WHO. Assessment of fracture risk and its application to screening for postmenopausal osteoporosis. Report of a WHO study group. World Health Organ Tech Rep Ser. 1994;843:1-129.

26. Rodriguez S, Gaunt TR, Day IN. Hardy-Weinberg equilibrium testing of biological ascertainment for Mendelian randomization studies. Am J Epidemiol. 2009;169:505-514.
27. Gaunt TR, Rodríguez S, Day IN. Cubic exact solutions for the estimation of pairwise haplotype frequencies: Implications for linkage disequilibrium analyses and a web tool 'CubeX'. BMC Bioinformatics. 2007;8:428

28. Khoury MJ, Beaty TH, Cohen BH. Fundamentals of Genetic Epidemiology. New York, NY: Oxford University Press; 1993.

29. Hosking L, Lumsden S, Lewis K, et al. Detection of genotyping errors by Hardy-Weinberg equilibrium testing. Eur J Hum Genet. 2004;12: 395-399.

30. Bai XC, Lu D, Bai J, et al. Oxidative stress inhibits osteoblastic differentiation of bone cells by ERK and NF-KB. Biochem Biophys Res Commun. 2004;314:197-207.

31. Mody N, Parhami F, Sarafian TA, Demer LL. Oxidative stress modulates osteoblastic differentiation of vascular and bone cells. Free Radic Biol Med. 2001;31:509-519.

32. Almeida M, Ambrogini E, Han L, Manolagas SC, Jilka RL. Increased lipid oxidation causes oxidative stress, increased peroxisome proliferator-activated receptor- $\gamma$ expression, and diminished pro-osteogenic Wnt signaling in the skeleton. J Biol Chem. 2009;284:2743827448.

33. Kim WK, Meliton V, Bourquard N, Hahn TJ, Parhami F. Hedgehog signaling and osteogenic differentiation in multipotent bone marrow stromal cells are inhibited by oxidative stress. J Cell Biochem. 2010;111:1199-1209.

34. Basu S, Michaëlsson K, Olofsson H, Johansson S, Melhus H. Association between oxidative stress and bone mineral density. Biochem Biophys Res Commun. 2001;288:275-279.

35. Zeng H, Cao JJ, Combs GF. Selenium in bone health: Roles in antioxidant protection and cell proliferation. Nutrients. 2013;5:97-110.

36. Chen CJ, Huang HS, Lin SB, Chang WC. Regulation of cyclooxygenase and 12-lipoxygenase catalysis by phospholipid hydroperoxide glutathione peroxidase in A431 cells. Prostaglandins Leukot Essent Fatty Acids. 2000;62:261-268.

37. Chen CJ, Huang HS, Chang WC. Inhibition of arachidonate metabolism in human epidermoid carcinoma a431 cells overexpressing phospholipid hydroperoxide glutathione peroxidase. J Biomed Sci. 2002;9:453-459.

38. Chen CJ, Huang HS, Chang WC. Depletion of phospholipid hydroperoxide glutathione peroxidase up-regulates arachidonate metabolism by 12 (S)-lipoxygenase and cyclooxygenase 1 in human epidermoid carcinoma A431 cells. FASEB. 2003;17:1694-1696.

39. Odabasi E, Turan M, Aydin A, Akay C, Kutlu M. Magnesium, zinc, copper, manganese, and selenium levels in postmenopausal women with osteoporosis. Can magnesium play a key role in osteoporosis? Ann Acad Med Singapore. 2008;37:564-567.

40. Arikan DC, Coskun A, Ozer A, Kilinc M, Atalay F, Arikan T. Plasma selenium, zinc, copper and lipid levels in postmenopausal Turkish women and their relation with osteoporosis. Biol Trace Elem Res. 2011; 144:407-417. 